\title{
NEW EVIDENCE ON THE ORIGIN OF THE OLD WORLD COTTONS
}

\author{
J. B. HUTCHINSON
}

Empire Cotton Growing Corporation, Cotton Research Station, Namulonge, Uganda

Received I5.viii.53

\section{INTRODUCTION}

IN the Evolution of Gossypium (Hutchinson, Silow and Stephens, 1947) it was suggested that the true cottons owe to human agencies their separation from the nearest wild species, their specific differentiation, and their striking evolutionary success. It followed that the whole of the diversification of the lint bearing species of Gossypium must be regarded as having taken place since the dawn of civilisation, and that the modern cottons represent the product of an extremely rapid evolutionary process. Further progress has now been made in the elucidation of the relationships of the Old World cottons (Hutchinson, I949, I950), and of their wild relatives (Knight, I949; Douwes, I95I; Douwes and Cuany, I95I, and I952), and a fresh assessment of the evidence on the origin and antiquity of the diploid cottons is therefore appropriate.

\section{THE RELATIONSHIP OF THE DIPLOID COTTONS TO THE WILD SPECIES}

There are two groups of wild species of Gossypium native to Africa and Asia, the Anomala and the Stocksiana. Since the Old World cottons are fairly closely related to the former, and only very distantly to the latter, an understanding of the relationships of the wild species is a prerequisite to a discussion of the origin of the cottons. Recently Douwes (I95I) has shown that G. somalense belongs in the Stocksiana, and Knight (1949) has recorded that it is distributed from northern Kenya to British Somaliland, and across the northern Sudan as far west as Ennedi in the eastern districts of French Equatorial Africa. Douwes and Cuany (1952) have shown that G. areysianum, formerly included in the Anomala on the original somewhat cursory description, also belongs morphologically and cytogenetically in the Stocksiana. Further, they have shown that $G$. triphyllum belongs in the Anomala, and the Anomala can now be defined with confidence as including G. anomalum and G. triphyllum only. Both species occur in arid regions in southern Angola and South-West Africa, and $G$. anomalum is distributed across the southern Sahara from the French Sudan to the upper reaches of the valley of the Baraka river in Eritrea. The distribution of these species is mapped in fig. 1 .

Hutchinson, Silow and Stephens (1947) suggested that the Old 
World cottons of the Section Herbacea arose under cultivation in Sind. Believing at that time that the Arabian G. areysianum belonged in the Anomala, they supposed that the original range of the Section included southern Arabia and the Red Sea region, and that the material first cultivated in Sind might have been collected by travellers to Arabia and neighbouring regions. It is now evident that the Arabian and Red Sea region is the territory of the Stocksiana and not of the Anomala, and the source of any parent type related to the Anomala must be sought far to the west or south west. The hypothesis that the prototype of the Herbacea existed in the Red Sea and Arabian region thus becomes untenable.

Cytologically the A genom of the Asiatic cottons and the B of the Anomala are the two most closely related of the genoms into which Beasley (1942) divided the genus Gossypium. In fact, but for

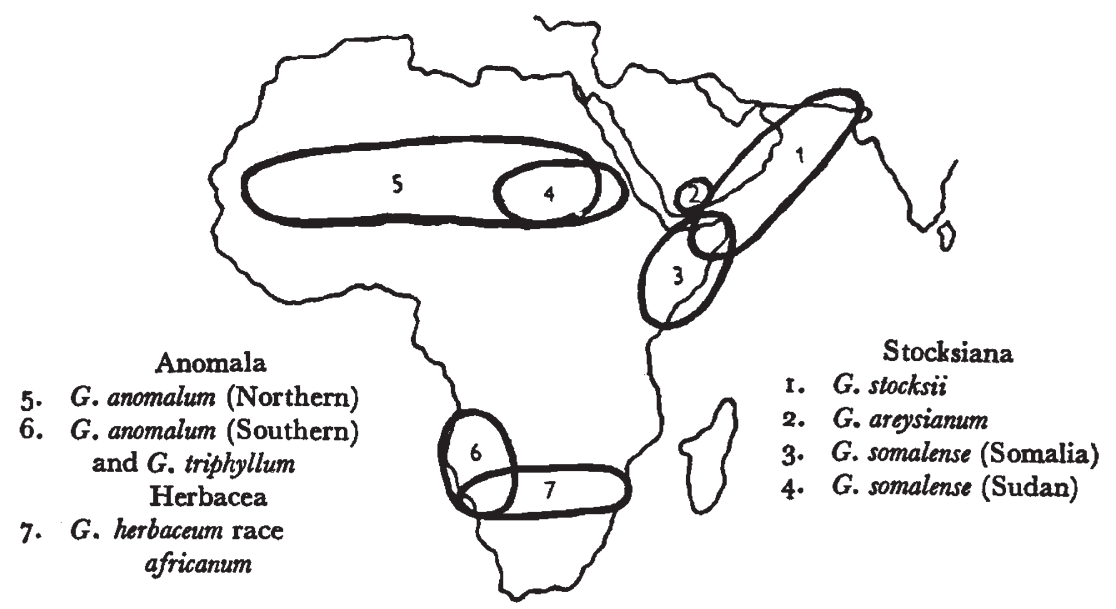

Fic. 1.-Distribution of Wild Species of Gossypium in Africa and Asia.

their radically different evolutionary status, they might have been regarded as scarcely sufficiently widely separated to justify equal rank with Beasley's other groups. In considering the genesis of the Herbacea, therefore, it is necessary to ignore the vast diversity of the cottons and the great extension of their range under cultivation in recent times, and try to reconstruct the status and distribution of the species of the A/B genoms before the intervention of man.

Considering the wild species of Gossypium only, there is good evidence for allopatric origin throughout the genus. Many species have distributions that do not overlap at all, and where overlapping occurs, it would be eliminated by a moderate contraction of the area now occupied. So it may be supposed that the first $\mathrm{A}$ bearing species was probably allopatric in relation to the early B species, and arose in some area adjacent to, but not within, that occupied by the early representatives of the Anomala. Since Gossypium is a genus of 
desert plants, this original area must have been in arid country. In so far as the distribution of the modern Anomala is a guide, there are two arid areas that may be considered. These are the SudanSomaliland region in the north, and the dry bushveld area stretching from Ngamiland to southern Portuguese East Africa in the south. In the former, there is nothing other than $G$. anomalum related to the Asiatic cottons, but two species of the Stocksiana are indigenous. It is, therefore, unlikely that the prototype of the true cottons was to be found there. The latter, on the other hand, though not occupied by any of the lintless species of Gossypium, is the habitat of a true cotton, Gossypium herbaceum, race africanum (see fig. 1). This cotton is a perennial shrub without the distinguishing characters of the modern agricultural races of the species, and is to be found growing wild in natural vegetation. Reasons have been given, however, (Hutchinson, Silow and Stephens, 1947; Hutchinson, 1949) for believing that it is a wild derivative of a cultivated race, and the evidence must be re-examined in detail before it can be considered as a possible primitive type close to the ancestral form of the Old World cottons.

With the exception of africanum, the introduction of all the cottons now to be found in Africa can be traced with some confidence. The account (Hutchinson, 1949) of those of northern Africa requires no modification. On the cottons of eastern and southern Africa, some further information is now available. A description of the coast of East Africa in ${ }_{15} 16$ A.D. by Duarte Barbosa (Hakluyt Society, 1866) includes an account of the use of cotton in the region of Sofala. According to Barbosa, the "Moors" of Sofala traded cotton goods and some silk, obtained from Cambay (in Western India) by way of the East African ports of Malindi, Mombasa and Kilwa, for gold from the kingdom of Monomotapa. He continues,

"The Moors have now recently begun to produce much fine cotton in this country, and they weave it into white stuff because they do not know how to dye it, or because they have not got any colours ..."

This account of the initiation of cotton cultivation on the East African coast fits in with the known distribution of $G$. arboreum race indicum. It has been pointed out (Hutchinson, 1950) that the indicum cottons of the East African coast and Madagascar resemble the Rozi cottons of Western India, as would be expected if they were introduced from the kingdom of Cambay. Moreover, they are still to be found on the coasts and islands of East Africa as far north as Somalia, which is in agreement with Barbosa's statement that the trade route was by way of Malindi, Mombasa, and Kilwa. Thus cotton spinning on the East African coast can be regarded as a comparatively recently introduced craft, associated in both origin and distribution with G. arboreum race indicum from Western India, and not with $G$. herbaceum race africanum.

The africanum cottons have also been further studied recently, 
Quintanilha et al. (1948) found the northern limit of the race in Portuguese territory was the Save River. It is to be found further north on the Rhodesian side of the border, and Quintanilha has recently (in correspondence) recorded it in Portuguese territory as far north as the Buzi River, and (as a single plant) on the right bank of the Zambesi at Garinde. In all cases it was found in open savannah forest and grassland associations. This area covers the localities from which herbarium material has been collected, and obviates the argument (Hutchinson, 1949) that africanum has suffered in recent times a diminution of area to be ascribed to the abandonment of cultivation. Moreover, Mr Gomes Pedro has pointed out (in correspondence) that "if it is really an introduced plant" it is surprising that "it disappeared almost completely along the known roads of penetration of pre-European merchants in spite of the fact that apparently the same ecological conditions as in Sul do Save are to be found in some patches along these roads." This is a particularly relevant comment, since elsewhere in Africa where cultivated cottons have run wild they are to be found on field margins, in house yards, and in the secondary associations that develop when natural vegetation is disturbed by man. It thus appears that the argument that africanum is a wild derivative of a cultivated cotton can no longer be sustained.

\section{The evidence of the bollworms}

Positive evidence that africanum is indigenous in southern Africa has recently been provided by studies of the taxonomy of the Red and Sudan bollworms. The Red bollworm pest was first described as Diparopsis castanea on a specimen from Delagoa Bay. It is known from Portuguese East Africa and neighbouring regions of South Africa, Rhodesia and Nyasaland. Recently, following the extension of cotton growing in Portuguese East Africa, it has appeared in the Rovuma river valley, and has gained a foothold in southern Tanganyika. What was believed to be the same insect is a well-known pest of cotton across the savannah belt of West Africa and in the Sudan, where it is known as Sudan bollworm. Since these bollworms are confined to cotton, and to the South African Cienfugosia hildebrandtii, their distributions provide information on the original distribution of their host plants.

Recently the classification of Diparopsis has been re-examined (Clements, I95I ; Pearson, 1954), and four species recognised. Of these the cotton pest of the savannah regions of West Africa and the Sudan is assigned to $D$. watersi, accessions from Angola to $D$. tephragramma, and moths bred from larvæ found on Gossypioides kirkii in Tanganyika are named $D$. gossypioides. $D$. castanea proper is the Red bollworm of South Africa, Portuguese East Africa and Nyasaland.

From the point of view of the student of evolution it is unfortunate that work on Diparopsis has been so largely confined to studies of its 
occurrence on cultivated cottons. The host range has, however, been worked out for $D$. castanea (Marshall, Parsons and Hutchinson, I937), and it is known that this species is confined to cultivated cottons, spontaneous $G$. herbaceum race africanum, and Cienfugosia hildebrandtii. The cultivated cottons are introductions of the last four centuries, and therefore represent recent additions to the host range. Diparopsis is not found in the northern part of the range of Cienfugosia hildebrandtii but only where the distribution of the Cienfugosia overlaps that of the africanum cottons. It may be concluded, therefore, that the Cienfugosia is not a primary host.

Of the other three species, $D$. gossypioides is only known from a few specimens collected from Gossypioides kirkii. D. tephragramma has been collected from cultivated cotton in Angola (Pearson, personal communication), and $D$. watersi is a pest of cultivated cotton in the West African and Sudan region. In the area of all species cotton is introduced and, as in southern Africa, must be regarded as a relatively recent addition to the host range of Diparopsis. Unfortunately, there is no direct evidence as to the original hosts of $D$. tephragramma and $D$. watersi. It seems probable that $D$. tephragramma depended on Gossypium triphyllum or G. anomalum, as these two species are indigenous in the area in which $D$. tephragramma occurs.* Similarly, $D$. watersi may be supposed to have lived on $G$. anomalum in the northern part of the range of the latter. Observations on $G$. anomalum in the northern Sudan indicate that it is attacked by bollworms in the wild as well as in experimental plots, but no opportunity has arisen of searching for Sudan bollworm on colonies of $G$. anomalum growing in areas remote from commercial cotton cultivation.

The three species of Diparopsis that attack cultivated cottons are all to be found in similar ecological zones, and the habits and life histories of $D$. perditor and $D$. castanea (the only two that have been adequately studied) are virtually the same (Geering and Baillie, in press). Only in terms of isolation on three distinct hosts can the emergence of three distinct species of Diparopsis be understood. It follows that a distinct host plant must have existed in the area originally occupied by $D$. castanea for a period long enough for the evolution of the species. This can only have been $G$. herbaceum race africanum, and race africanum must, therefore, be an ancient truly wild plant, and not a recent escape from cultivation.

\section{THE ORIGIN OF THE CULTIVATED DIPLOID COTTONS}

Having given reasons for believing that one diploid cotton is truly wild, it becomes necessary to re-examine the possibility that others may be also. In $G$. herbaceum there are no other forms concerning

\footnotetext{
* A Red bollworm egg was observed on a herbarium specimen of $G$. triphyllum (Parnell, personal communication) some years before it was found that there was more than one species of Diparopsis.
} 
which there can be any doubt. Chevalier (1936) and Hutchinson (1949) have shown that the north African $G$. herbaceum race acerifolium is never found beyond the shelter afforded, directly or indirectly, by man's agricultural activities. Data on recent collections and herbarium material from Arabia indicate that race acerifolium is an associate of man there also. The other races of the species have only been recorded in cultivation.

Forms of $G$. arboreum have been recorded growing spontaneously in many areas, and the possibility that the species was independently domesticated from the wild requires careful consideration. The most important collections of spontaneous arboreum cottons are those from Western India and the Deccan discussed by Watt (1907). In considering his views it must be remembered that he considered it natural that wild cottons should be found alongside cultivated forms. In discussing $G$ : arboreum, he stated firstly that

"It is doubtful whether any botanist has ever discovered it in what could be regarded as an undoubted indigenous habitat in any country ", and then went on to say : "Thus while little is known for certain of the origin of Gossypium arboreum there seems no doubt whatever that it played an important role in the production of some of the best-known cultivated cottons of the Old World. It is accordingly desirable to assume the existence of a wild species, such as that briefly indicated by the older authors. And in part support of that view it may be added that when neglected, the cultivated forms become perennials and rapidly assume the leading characteristics of the plant briefly defined above, . . ."

When such views obtained there could be no recognition of the need to distinguish critically between plants occurring more or less spontaneously in secondary man-made habitats, and those having an established place in undisturbed indigenous vegetation. Watt (1907) collected cottons growing spontaneously in Kathiawar, Gujerat, Khandesh, and the Deccan. He stated,

"I have in India repeatedly collected a wild or self-sown Gossypium. . . It literally envelops the old fort of Junagardh and the subterranean Buddhist palaces of that neighbourhood. It is common on the sacred Jaina hill of Palitana growing among the indigenous scrubby vegetation where, for some centuries possibly, there has been no cultivation. It is fairly common in the hedges of Gujerat . . . and was found by me in Khandesh and in the Deccan, especially near the Buddhist cave temples of Elura and Ajunta. If in all these instances it has to be regarded as but a survival of former cultivation, there would seem every likelihood that in some of its known habitats it has existed in that condition for a great many years, perhaps centuries."

Of Rozi, the cultivated form of this perennial, Watt stated, "When left to grow in the hedgerows rozi becomes subscandent, the wool shortens and turns rufous-coloured, and the fuzz lengthens and also becomes red-coloured." Evidently there is no sharp distinction between the wild growing and cultivated forms, and the habitats of those found wild are all on cultivation margins or on the abandoned sites of human activity. More recently, Chevalier (1936) and Hutchinson (1949) have examined the status of $G$. arboreum race soudanense in the field in West Africa and the Sudan, and concluded that it is entirely 
dependent on cultivation or on the secondary habitats opened up thereby. There is thus a close parallel between the habits of the Indian and African forms of $G$. arboreum, and it may be concluded that in both regions the species is always a cultigen or is derived from a cultigen.

Cottons of the species $G$. arboreum have been reported as wild in the Indonesian archipelago and the Philippines. Herbarium material of most of the morphologically distinct forms of $G$. arboreum is available from Indonesia, and much of it is known to have been cultivated. The only living material that has been examined consists of one perennial form from the Philippines, said to be wild, and two accessions of a cultivated annual known as Demak from Java. Types that were probably perennial are represented by specimens from Ticao in the Philippines, British North Borneo, Gorontalo and Macassar in the Celebes, and the islands of Leti, Lakor and Timor. Probable annuals, mostly known to be cultivated, have been collected in Culion and Panay in the Philippines, and from a number of places in Java. Evidently cottons have been sufficiently widely spread and used in the area to account for the presence of forms that have run wild. Though direct evidence of the dependence of such types upon man is lacking, the possibility that they might be truly wild and endemic can be ruled out on ecological grounds. It has been shown repeatedly (Hutchinson, Silow, and Stephens, I947; Hutchinson, I943; Hutchinson, 1944) in various parts of the world that the genus Gossypium is xerophytic, and that even its most mesophytic members are intolerant of competition, particularly in the seedling stage. In southern Africa $G$. herbaceum race africanum is to be found in open vegetation in areas with rarely more than 30 inches of rain. In western India $G$. arboreum race indicum has established itself in regions of similar rainfall and correspondingly open vegetation. In the Indonesian and Philippine region, areas with a dry season are limited, and even these rarely receive less than 40 inches of rain per annum. To quote Braak (I945), "A yearly amount of less than $1000 \mathrm{~mm}$. is quite exceptional ", and has in fact only been recorded at four rainfall stations in Indonesia. In such conditions the height and density of natural climax vegetation would preclude the establishment of any member of the genus Gossypium, and it may be concluded that the cottons were introduced by man and are maintained, directly or indirectly, by his activities.

G. arboreum has been recorded as wild in Madagascar. From herbarium specimens and living material grown from Madagascar seed, the type can be assigned with confidence to $G$. arboreum race indicum.* It is in fact indistinguishable from perennial forms from western India. In parts of the island it has been maintained in house yards and even cultivated until recent times. Plants were raised

* G. herbaceum I. var. perrieri Hoch. and G. mahafalense have been used for Madagascar collections. 
from two accessions of seed. They were tall, late fruiting perennials, and were very similar in appearance, except that the one recorded as wild was later fruiting. There was obviously a very close relationship between the two, and the question is simply whether the wild is derived from the cultivated or vice versa.

M. Perrier de la Bathie has summarised in correspondence existing knowledge of the status of $G$. arboreum in Madagascar. He pointed out that there are in north Madagascar remains of ancient (but undated) Hindu-Arab settlements, and in west Madagascar traces of an even older Bantu colonisation. G. arboreum is found throughout the length of the west coast in three forms, which he described as follows (trans. from French) :

" I. primitive form, arborescent, which no longer exists except in the xerophytic woodlands of the S.W. ;

“ 2. ruderal form, perennial, \pm planted by the natives in the vicinity of their villages, probably relics of ancient cultures ; and

" 3 . cultivated form, herbaceous, a culture which was still practised in 1900-12, and which may or may not continue at the present time." *

The distribution of the three forms is given in the map in fig. 2. It will be seen that the cultivation relic form extends throughout the area of the two ancient colonisations, while both the cultivated form and the "primitive form" now only found wild, are found in the southwest. The limitation of the "primitive form" to xerophytic woodlands is as would be expected. It is only in such habitats that Gossypium can maintain itself without the intervention of man. The status of $G$. arboreum in Madagascar is, therefore, consistent with the theory that it was introduced into the island as a cultivated plant, perhaps by the Hindu-Arab community, and became established as a secondarily wild plant in the xerophytic vegetation in the southwest of the island. The alternative, that the wild arboreum of southern Madagascar is the primitive form of the species, cannot be ruled out on present evidence. That $G$. arboreum originated in the wild just across the sea from the endemic area of $G$. herbaceum race africanum is an attractive hypothesis, and a close study of the species in Madagascar with this possibility in mind would be instructive. Nevertheless, the genetic evidence is in conformity with that adduced above from morphological and geographical considerations in supporting the view that $G$. arboreum in Madagascar was derived from Indian forms, and not the reverse. G. arboreum and $G$. herbaceum are so closely allied as to give vigorous, fully fertile $F_{1} s$, and the species barrier only acts through genetic breakdown in later generations. It will be shown below that the closest relationship is between the arboreums of western India and $G$. herbaceum race acerifolium from Arabia, and not the wild africanum from southern Africa, and it will be suggested that between the Arabian and Indian forms the species barrier may well prove to be of little account. The weight of evidence is therefore in

* Among accessions from Madagascar grown since this was written, the annual form proved to be $G$. hirsutum race punctatum. 
favour of the view that $G$. arboreum was never truly wild, but arose in cultivation by differentiation from a cultivated stock of $G$. herbaceum.

The development of the cultivated races of $G$. herbaceum took place

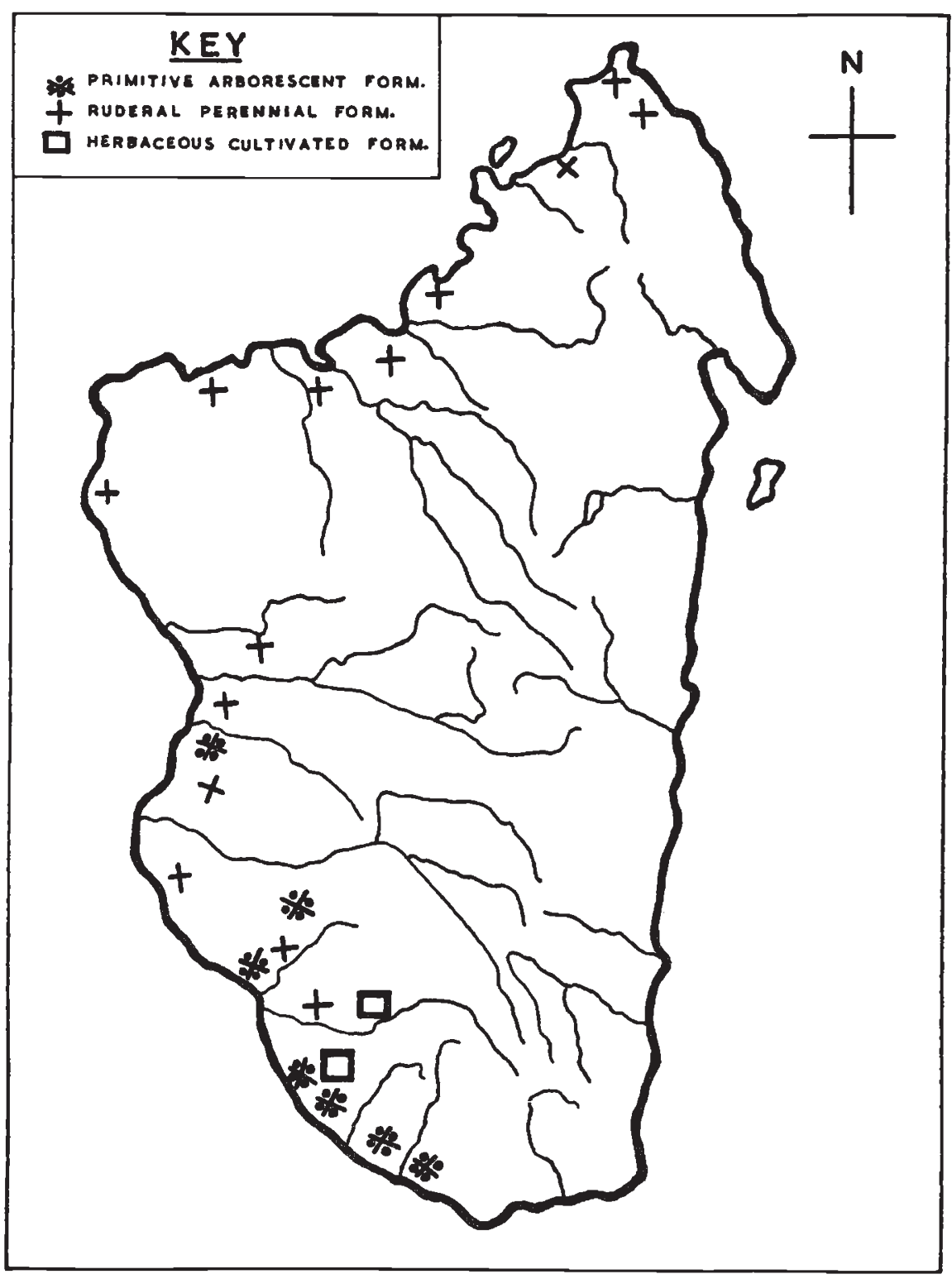

Fro. 2.-Outline map of Madagascar showing records of $G$. arboreum race indicum after M. Perrier de la Bathie.

far to the north of the area in which the wild G. herbaceum race africanum is now to be found. (see distribution map, fig. 3.) There seems no reason to suppose that the range of africanum was ever so extended, 
and there is no evidence that any form of $G$. herbaceum was wild in any of the territories in which it is now either cultivated or commensal. It seems probable, therefore, that the wild plant was introduced into the country in which it was first domesticated. Trade between India and Arabia and the East African coast is very ancient and gold from the region in which $G$. herbaceum race africanum is wild was important in it. It may well be, therefore, that wild cotton was taken home by traders from the north who were primarily interested in other things.

It has been suggested (Hutchinson, Silow and Stephens, 1947) that the cultivated cottons arose in the lower Indus valley, in what is now Sind. The native cottons of Sind in recent times belong to G. arboreum. Evidence on the early cottons of the Indus valley is limited to that gleaned by Gulati and Turner (1928) from three

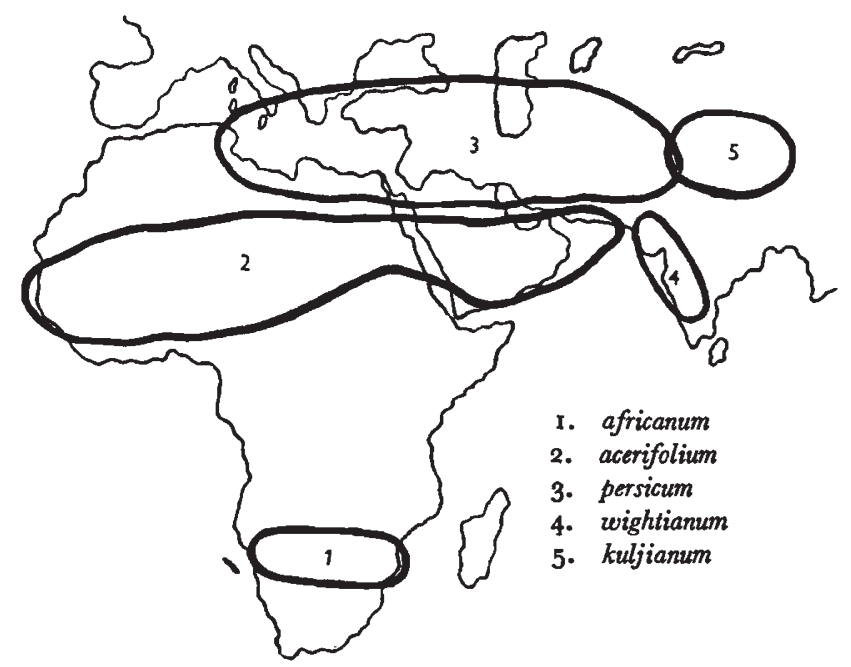

Fic. 3.-Distribution of Races of Gossypium herbaceum.

fragments of cotton materials recovered from the ruins of Mohenjo Daro and dated c. $3000-2750$ B.c. They concluded that the lint hair characters of the ancient cotton resembled those of coarse arboreum cottons of the present day, and not those of modern Indian herbaceums. If the original lint bearing cotton was a wild type of which $G$. herbaceum race africanum is the modern representative, the theory that domestication took place in Sind is untenable.

The earliest cottons must be sought within the present range of G. herbaceum. The most primitive of the cultivated herbaceums are the perennials related to race acerifolium. Cottons of this type are to be found all the way from the Mekran in Baluchistan (Ansari, 194I) through Arabia, and across the Sahara to West Africa. They appear to have been introduced into Africa by the Moslems (Hutchinson, 1949), and their original home may be taken to be Arabia or the 
coasts of Persia and Baluchistan. Thus the most primitive cultivated herbaceumis are to be found on the coasts bordering the great Indian Ocean trade route by which it must be supposed that the introduction of their wild ancestor from southern Africa was effected. From thence, the differentiation of the herbaceum cottons took place under the selective pressure of new environments as the new crop spread. In Persia, the annual race persicum was developed to meet the limitations imposed by cold winters, and further north the very short term race kuljianum arose in response to selection in an area of short, hot summers and long, cold winters. Later, when the advantages of the annual habit became apparent in India, annual herbaceums were carried south to replace perennial arboreums and gave rise to race wightianum in western India.

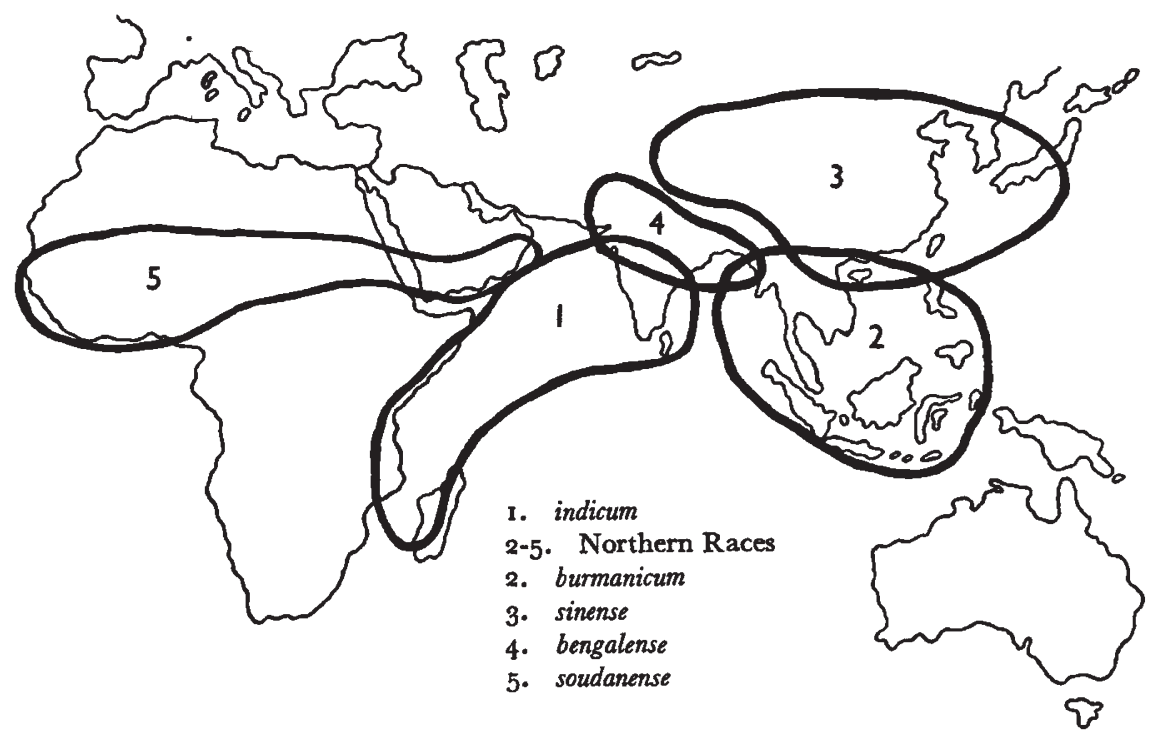

Frg. 4.-Distribution of Races of Gossypium arboreum.

In considering the origin and development of G. arboreum, the species may be divided into two parts. On the one hand are the indicum cottons of peninsular India. Among these are to be found both the primitive perennial forms that were collected in wild secondary vegetation by Watt, and also the annual high quality cottons of the crops of the Deccan and Madras. On the other hand are the burmanicum cottons of Assam and Burma, and related perennials to be found occasionally throughout the Ganges valley and neighbouring regions, Rajputana, the southern Punjab, and Sind. From this perennial group arose two great annual races, the bengalense cottons of the commercial crops of northern India and the sinense cottons of China (see distribution map, fig. 4).

Silow (1944) showed that genetically race indicum is more closely related to $G$. herbaceum than are the other races of $G$. arboreum. This 
conclusion is supported by morphological data. Watt (1907) classified the perennial forms of $G$. arboreum race indicum as $G$. obtusifolium, and made wightianum a variety of it. There can be no doubt now that the perennial indicums belong in $G$. arboreum, and the annual wightianums in $G$. herbaceum, but they are nevertheless not very widely distinct. Even closer morphologically are the perennials of $G$. herbaceum race acerifolium from Arabia and the perennials of $G$. arboreum race indicum from western India. Indeed, in the absence of fruiting material it is often impossible to say with confidence whether an Arabian specimen of this type belongs in G. arboreum or G. herbaceum. On any theory of the differentiation of $G$. arboreum and $G$. herbaceum, these two must be regarded as the types linking the species.

These perennial indicums are to be found in profusion in Kathiawar and Gujerat in Western India. Southwards throughout peninsular India primitive forms are occasional, and more advanced perennial forms not uncommon, while the great commercial crops are planted with their annual derivatives. From the distribution of the more primitive types it is clear that the centre of the race is in Kathiawar and Gujerat, and it has spread thence into peninsular India. Cambay is in the ancient home of the race, and from Cambay it spread also along the Indian Ocean trade route to the East African coast and, it is suggested, also to Madagascar.

G. arboreum race indicum is morphologically rather uniform. It tends to form rounded bushes when well grown, with broad leaves, little or no anthocyanin pigment, and yellow flowers. The perennial forms of $G$. arboreum from the Indo-Gangetic plain, and those of $G$. arboreum race burmanicum in Assam and Burma, are pyramidal shrubs with long flexible branches, and are highly variable in leaf shape, anthocyanin pigmentation, and flower colour. Because of the inadequacy of the available material, Silow was unable to assess the position of the north African $G$. arboreum race soudanense. Extensive further collections have been made, and it is now clear that the soudanense cottons are pyramidal shrubs with long flexible branches, and are, therefore, related to the arboreum cottons of northern India rather than those of race indicum. In addition they exhibit the variability in minor characters typical of the northern group.

Gulati and Turner's (1928) studies showed that in measurable characters the Mohenjo Daro cotton resembled modern cottons of the northern group rather than the indicums, and it may be suggested that the part played by the Indus civilisation in the rise of the cotton crop, which was undoubtedly an important one, was the development and spread of the northern arboreums. This group is the real backbone of the Old World cotton crop. Westward it gave the first cottons of Africa, first at Meroe on the Nile and later right across the savannahs of the Sudan to West Africa. Eastward it gave the cottons of the Ganges valley, Assam, and Burma, and thence gave rise to the two great annual races, bengalense in northern India, and 
sinense in China. Moreover, it appears that the cottons of Indonesia and the Philippines are of northern, and not peninsular, Indian origin. The only perennial form that has been grown in culture was of the pyramidal habit, and records of narrow leaf and red flower in Indonesian cottons are common in the literature. Perennials are well known in Burma, where they still contribute to the commercial crop, and they have also been collected in Siam. A careful study of Watt's quotations of specimens, however, reveals none from Malaya. Moreover, in both Indonesia and the Philippines cotton is known as "kapas" or "gapas" which is the northern Indian name for seed cotton (Sanskrit, Hindustani, Bengali, and related languages). Hence it is likely that the early northern cottons spread south eastward from Burma to Indonesia through Siam.

There is thus evidence of three waves of development in the Asiatic cottons. First came the evolution of domesticated forms of G. herbaceum in Arabia and Persia. Then followed the differentiation of $G$. arboreum race indicum in western India, and finally the northern arboreums of the burmanicum-soudanense group were evolved in the Indus region. Subsequent development went on in parallel in the three groups. Improvement in agricultural characters, the evolution of the annual habit, and the development of resistance to such diseases and pests as bacterial blight and jassid, can be seen in all three. Nevertheless the three stocks were not equally successful. The most recent has covered the greatest area, stretching from the Atlantic in West Africa to the Pacific in Japan, and has developed the largest crop populations, with the great bulk of the Chinese crop and of the crops of northern and central India to its credit. G. arboreum race indicum, which is more recent than G. herbaceum, has surpassed the older species in agricultural success, having provided the stock for the greater part of the crops of peninsular India. G. herbaceum, though it has spread rather widely in cultivation, has had only limited agricultural success. Only in the wightianums of western India has it become established in the extensive crops of modern agriculture.

\section{DISCUSSION}

Hutchinson, Silow and Stephens (1947) pointed out that the basic distinguishing feature of the true cottons is the possession of convoluted lint hairs on the seed. These true lint hairs can be spun, whereas the simple seed hairs of the wild species cannot. They supposed that convoluted hairs arose from simple hairs by mutation in a wild species, and that such a mutant type provided the basis for the evolution under human selection of the true cottons. It is now evident that the convoluted lint hair was established as a characteristic of a truly wild plant without the selective advantage of usefulness to man. The whole of the subsequent development of the cultivated diploid cottons of both species can, however, be accounted for by evolution under human selection. 
Rigorous proof of a theory of evolutionary development is rarely possible, but strong support is gained for it if it is used successfully for prediction. In the present instance there are certain consequences of the theory of the recent development of the cottons that can be put to the test. If $G$. herbaceum and $G$. arboreum had been separately domesticated from long established wild plants, the differentiation of the modern cottons would be no more than the most recent episode in the long history of each species. It would then be expected that the genotypic difference between the species would be large compared with that between races of the same species. On the theory that the two species were evolved under domestication from a common stock, however, the genotypic differences between and within species would be of a not very different order, and estimates of the magnitude of the species difference might be very different according to whether primitive or advanced stocks were used in the experiment.

The evidence on which the magnitude of the species distinction has been assessed is worth a brief review. Forms of G. herbaceum race wightianum are to be found growing mixed with $G$. arboreum race bengalense in western India, and with $G$. arboreum race indicum in Madras. Similar mixtures of $G$. herbaceum race kuljianum and G. arboreum race sinense have been reported from western China (Yu, quoted by Silow, 1944). In these mixed crops the two species maintain their integrity in spite of some crossing and the appearance of vigorous, fertile $F_{1}$ hybrids, and it thus appears that the species distinction is of a different order from the distinctions between races of the same species. The validity of the argument is amply supported by data from experimental material. Genetic breakdown in $F_{2}$ and later generations has been demonstrated in crosses between $G$. herbaceum race wightianum and $G$. arboreum race indicum, and between $G$. herbaceum race persicum and $G$. arboreum race bengalense. Moreover, attempts to produce agriculturally acceptable cottons from $G$. herbaceum race wightianum $\times$ G. arboreum race indicum crosses have failed repeatedly. All this information, however, has been collected from crosses between the most advanced agricultural stocks of the two species. No data are available from crosses between primitive perennials of $G$. herbaceum race acerifolium and $G$. arboreum race indicum, and if the belief that these represent an early stage in the separation of the species is correct, it is to be expected that such crosses would reveal much less genetic differentiation than has been found in crosses of more advanced stocks.

\section{SUMMARY}

I. New evidence on the relationships of the wild species of Gossypium of Asia and Africa is discussed. It is shown that the theory that the cultivated diploid cottons arose in cultivation in the lower Indus valley from a wild species brought from the eastern Sudan or Arabia is no longer tenable. 
2. Possible areas from which the ancestor of the diploid cottons might have come are surveyed, and it is shown that the most likely is the arid bushveld area of southern Africa stretching from Ngamiland to southern Portuguese East Africa. In this region G. herbaceum race africanum grows wild in natural vegetation.

3. The theory that $G$. herbaceum race africanum is an escape from former cultivations is reconsidered in the light of fresh historical evidence, and is shown to be without real support.

4. Recent research on the Red bollworm of cotton is considered, and it is shown that the evolution of Diparopsis castanea, which is endemic in southern Africa, can only have taken place on $G$. herbaceum race africanum, and it follows that $G$. herbaceum race africanum must have been established in southern Africa during the whole evolutionary history of the pest. It must, therefore, be truly wild and not a recent escape from cultivation.

5. The status of $G$. arboreum is considered, and it is shown that there is good reason to believe that it arose in cultivation by differentiation from $G$. herbaceum.

6. The history of the diploid cottons is interpreted in terms of three major assemblies of cultivated forms.

(i) The oldest, and least important in modern agriculture, is the assembly comprising the four cultivated races of $G$. herbaceum, races acerifolium, wightianum, persicum and kuljianum.

(ii) In G. arboreum, race indicum embraces the oldest forms and those most closely related to $G$. herbaceum. It provides the cottons for most of the commercial crop of Peninsular India.

(iii) The most recent, and agriculturally the most important of the three, is what may be called the northern Indian assembly, comprising four races of $G$. arboreum, races burmanicum, soudanense, bengalense and sinense. Of these, the two annual races, bengalense and sinense, provide the cottons that contribute the great bulk of the crops of northern India and China.

\section{APPENDIX}

Note on the Sections, Species and Races of Gossypium discussed in the text

The classification of the species and races of Gossypium has been progressively modified in recent years. The basic classification is that given by Hutchinson, Silow and Stephens (indicated below by H.S.S.) in The Evolution of Gossypium. Geographical distributions are given there also. Rearrangement below the species level has been proposed in several more recent papers, in which also some adjustments 
of distribution have been made in the light of recent additions to knowledge. A list of the Sections, species and races of Gossypium discussed is given below, together with references to the papers in which the names used were defined.

\begin{tabular}{|c|c|c|c|}
\hline Section & Species & Race & Reference \\
\hline ANOMALA & $\begin{array}{l}\text { G. anomalum } \\
\text { G. triphyllum }\end{array}$ & $\begin{array}{l}\cdots \\
\cdots \\
\cdots\end{array}$ & $\begin{array}{l}\text { H.S.S. } \\
\text { H.S.S. } \\
\text { Douwes and Cuany, } 1952\end{array}$ \\
\hline STOCKSIANA & $\begin{array}{l}\text { G. stocksii } \\
\text { G. areysianum } \\
\text { G. somalense }\end{array}$ & $\begin{array}{l}\cdots \\
\cdots \\
\cdots\end{array}$ & $\begin{array}{l}\text { H.S.S. } \\
\text { H.S.S. } \\
\text { Douwes and Cuany, 1952 } \\
\text { Knight, } 1949 \text {; Douwes, } 1951\end{array}$ \\
\hline HERBACEA & G. herbaceum & $\begin{array}{l}\text { africanum } \\
\text { acerifolium } \\
\text { wightianum } \\
\text { persicum } \\
\text { kuljianum } \\
\text { indicum } \\
\text { soudanense } \\
\text { burmanicum } \\
\text { bengalense } \\
\text { sinense }\end{array}$ & $\begin{array}{l}\text { H.S.S. } \\
\text { Hutchinson, 1949; } 1950 \\
\text { Hutchinson, } 1949 ; 1950 \\
\text { Hutchinson, } 1950 \\
\text { Hutchinson, 1950 } \\
\text { Hutchinson, 1950 } \\
\text { Hutchinson, 1949; } 1950 \\
\text { Hutchinson, } 1949 ; 1950 \\
\text { H.S.S. } \\
\text { H.S.S. } \\
\text { H.S.S. }\end{array}$ \\
\hline
\end{tabular}

\section{REFERENCES}

ANSARI, M. A. A. 194I. Survey of cottons of Baluchistan. Ind. F. Agric. Sci., II, 59. BARBOSA, DUARTE. I866. A description of the coasts of East Africa and Malabar at the beginning of the 16 th century. Trans. by H. E. J. Stanley, Hakluyt Soc. BEASLEY, J. O. 1942. Meiotic chromosome behaviour in species, species hybrids, haploids, and induced polyploids of Gossypium. Genetics, 27, 25.

BRAAK, c. I945. On the Climate of and Meteorological Research in the Netherlands Indies. In Science and Scientists in the Netherlands Indies. Board for the Netherlands Indies, Surinam and Curacao.

Chevalier, A. 1936. La Systemique des Cotonniers originaire de l'Ancien Monde. Rev. Bot. App. Agr. Trop., 16, 546.

Clements, A. N. 1951. A revision of Diparopsis Hmps. (Agrotidæ, Lepidoptera). Bull. Ent. Res., 42, 491.

DouwEs, H. I951. The cytological relationships of Gossypium somalense Gurke. 7. Genet., 50, 179.

DouWes, H., AND GUANY, R. L. 1951. Progress report on cytogenetics. In P.R. from Exp. Stations, E.C.G.C., London.

DouWES, H., AND GUANY, R. L. 1952. Progress report on cytogenetics. In P.R. from Exp. Stations, E.C.G.G., London.

GeEring, Q. A., AND Baillie, A. F. H. The Biology of Red Bollworm, Diparopsis watersi Rothschild, in Northern Nigeria. (In press.)

GULATI, A. N., AND TURNER, A. J. 1928. A note on the early history of cotton. Ind. Cent. Cotton Cttee., Tech. Lab. Bull. No. 17.

Hutchinson, J. B. 1943. Note on the native cottons of Trinidad. Trop. Agr., $20,235$.

hutchinson, J. в. 1944. The cottons of Puerto Rico. Puerto Rico Agric. 7., $28,35$. hutchinson, J. B. 1949. The dissemination of cotton in Africa. Emp. Cotton Gr. Rev., $26, \mathrm{I}$.

HUTCHINson, J. B. 1950. A note on some geographical races of Asiatic cottons. Emp. Cotton Gr. Rev., 27, 123. 
Hutchinson, J. B., SILOW, R. A., AND STEPHENS, S. G. 1947. The Evolution of Gossypium. Oxford Univ. Press.

кNIGHT, R. L. I949. The distribution of wild species of Gossypium in the Sudan. Emp. Cotton Gr. Rev., 26, 1 .

MARShall, J., PARSONS, F. S., AND hUTChinson, H. I937. Ecology of food plants of Diparopsis castanea. Bull. Ent. Res., $28,62 \mathrm{I}$.

PRARson, 8. O. 1954. The relationship between the African and South American Red Bollworm of cotton, Diparopsis and Sacadodes. Emp. Cotton Gr. Rev., 3I, 3 . QUINTANILHA, A., BEATRIZ, M. G., AND DE EGA, L. s. I948. Variedades de Algodao Cultivadas em Mocambique. Trabalhos do Centro de Investigacao Cientifica Algodonira $\mathrm{I}, 6$, Lourenco Marques.

sizow, R. A. I 944 . The genetics of species development in Old World cottons. J. Genet., 46,62 .

Watr, G. 1907. The Wild and Cultivated Cotton Plants of the World. Longmans. 